\title{
STUDI KELAYAKAN THEME CENTER DI AREA PELABUHAN SUNDA KELAPA, JAKARTA UTARA
}

\author{
Kelvin Aulia ${ }^{1)}$, Priyendiswara A.B ${ }^{2)}$, Liong Ju Tjung ${ }^{2)}$
}

\footnotetext{
1)Program Studi S1 PWK, Fakultas Teknik, Universitas Tarumanagara, kelvinauliaaa9@gmail.com

2)Program Studi S1 PWK, Fakultas Teknik, Universitas Tarumanagara, priyendiswaraa@ft.untar.ac.id

3)Program Studi S1 PWK, Fakultas Teknik, Universitas Tarumanagara, jt.liong@pps.untar.ac.id
}

\begin{abstract}
Abstrak
Pelabuhan Sunda Kelapa merupakan pelabuhan yang berlokasi di Kecamatan Penjaringan, Kelurahan Penjaringan, Jakarta Utara yang dahulu bernama Pelabuhan Kalapa pada abad ke 12 dan merupakan pelabuhan terpenting Kerajaan Pajajaran. Kemudian pada masa masuknya Islam dan para Penjajah dari Eropa, Pelabuhan Kalapa diperebutkan antara kerajaan-kerajaan Nusantara dan Eropa. Pada tahun 1970 setelah Belanda berhasil menguasai daerah tersebut dan sekitarmya membuat nama pelabuhan Kalapa berubah menjadi Pelubahan Sunda Kelapa. Mengingat Pelabuhan Sunda Kelapa dan daerah sekitarnya merupakan wilayah dengan nilai sejarah yang tinggi menyebabkan diterbitkannya rencana induk kawasan kota yang tertera pada Peraturan Gubernur DKI Jakarta No. 36 Tahun 2014. Peraturan Gubernur tersebut menetapkan Pelabuhan Sunda Kelapa akan dikembangkan menjadi kawasan pariwisata sejarah dan akan dikembangkan fasilitas komersial di dalamnya. Tujuan umum penelitian ini adalah untuk melakukan studi kelayakan pengembangan fasilitas komersial di Pelabuhan Sunda Kelapa. Studi kelayakan tersebut terdiri dari analisis lokasi, legalitas, pasar dan investasi. Penulisan ini lebih menekankan pada analisis lokasi, analisis legalitas dan analisis pasar yang akan memperlihatkan potensi dari pengembangan yang akan dilakukan pada bagian mall terbatas. Hasil kajian ini diharapkan dapat memberi masukan kepada pihak yang akan melakukan pengembangan proyek di area Pelabuhan Sunda Kelapa tepatnya pada bagian mall terbatas dengan konsep Theme Center.
\end{abstract}

Kata kunci: Fasilitas komersial; Kawasan pariwisata sejarah; Theme Center

\begin{abstract}
Sunda Kelapa Harbor is a port located in Penjaringan Subdistrict, Penjaringan Village, North Jakarta, which was formerly called Kalapa Port in the 12th century and is the most important port of the Kingdom of Pajajaran. Then at the time of the entry of Islam and the invaders from Europe, the Port of Kalapa was contested between the Archipelago and European kingdoms. In 1970 after the Dutch succeeded in taking control of the area and around it made the port name of Kalapa transform into Sunda Kelapa Substitution. Considering that the Sunda Kelapa Port and the surrounding area are regions with high historical values, the issuance of the city area master plan is stated in the DKI Jakarta Governor Regulation No. 36 of 2014. The Governor's Regulation stipulates that the Sunda Kelapa Port will be developed into a historical tourism area and commercial facilities will be developed in it. The general objective of this study is to conduct a feasibility study on the development of commercial facilities in Sunda Kelapa Port. The feasibility study consists of location, legality, market and investment analysis. This writing places more emphasis on location analysis and market analysis that will show the potential of development to be carried out in a limited section of the mall. The results of this study are expected to provide input to those who will develop the project in the area of Sunda Kelapa Port precisely in the limited mall section with the concept center.
\end{abstract}

Keywords: Commercial facility; Historical tourism area; Theme center

\section{PENDAHULUAN}

Kota Jakarta Utara memiliki luas sebesar $137 \mathrm{~km}^{2}$ dengan total 6 kecamatan dengan penduduk sebesar 1.706.281 jiwa dan kepadatan penduduk sebesar 12.456,61 Jiwa merupakan 
salah satu wilayah administrasi di provinsi DKI Jakarta yang pusat pemerintahannya berada di Koja. Di sebelah utara Jakarta Utara berbatasan dengan laut Jawa, disebelah timur dengan Bekasi, di bagian selatan berbatasan dengan Jakarta Barat, Jakarta Pusat dan Jakarta Timur dan pada bagian barat berbatasan dengan Tangerang.

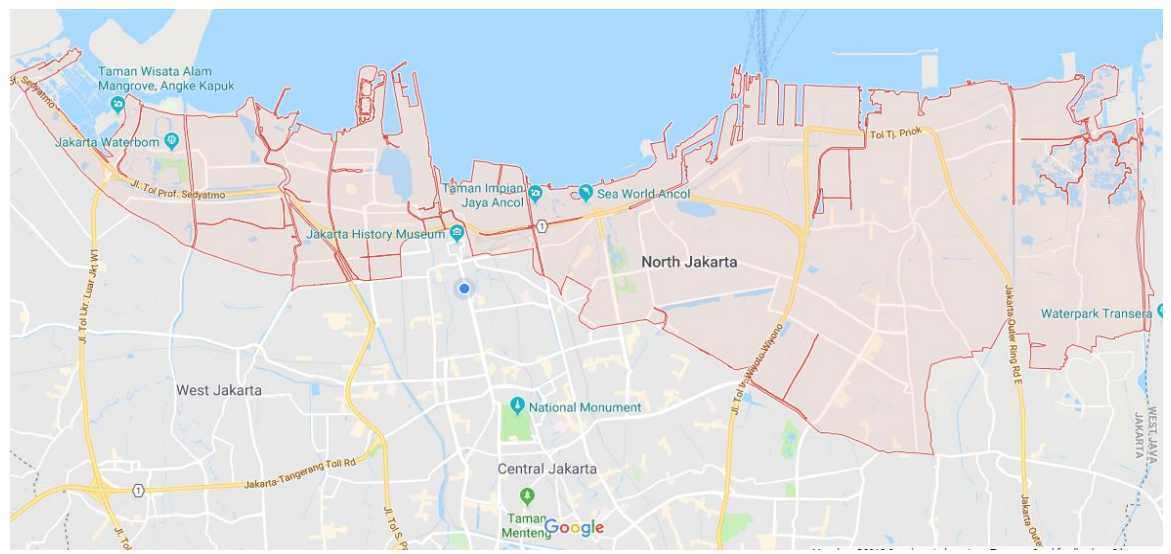

Gambar 1. Peta Wilayah Administrasi kota Jakarta Utara

Sumber : googlemaps.com

Dengan letaknya yang berada paling dekat dengan laut Jawa membuatnya menjadi tempat yang strategis dalam pengembangan pelabuhan. Saat ini di Jakarta terdapat 7 pelabuhan yang beroperasi sampai saat in yang terdiri dari pelabuhan Tanjung Priuk, pelabuhan Marina, pelabuhan Muara Angke, pelabuhan Marunda, pelabuhan Sunda Kelapa, Pelabuhan Muara Baru dan pelabuhan Pantai Mutiara Jakarta. Salah satu pelabuhan yang sudah berdiri sejak jaman dahulu adalah pelabuhan Sunda Kelapa yang sampai saat ini sudah beroperasi dan menjadi salah satu objek sejarah di wilayah Jakarta. Mengingat Pelabuhan Sunda Kelapa dan daerah sekitarnya merupakan wilayah dengan nilai sejarah yang tinggi membuat diterbitkannya Rencana Induk Kawasan Kotatua yang tertera pada Peraturan Gubernur DKI Jakarta No. 36 Tahun 2014 dan Pelabuhan Sunda Kelapa masuk kedalam rencana induk tersebut. Pelabuhan Sunda Kelapa sendiri sekarang berubah menjadi salah satu objek wisata sejarah dan akan mengalami pengembangan di dalamnya.

Maksud dari penelitian ini adalah untuk melakukan studi kelayakan fasilitas komersial berupa mall terbatas di Pelabuhan Sunda Kelapa sehingga dapat memberikan rekomendasi mengenai jenis properti apa yang akan dikembangkan.

Lalu tujuan umum penelitian ini adalah untuk membuat studi kelayakan fasilitas komersial berupa mall terbatas di Pelabuhan Sunda Kelapa. Sedangkan tujuan khusus penilitian ini yaitu untuk mengetahui potensi dan masalah objek studi yang akan dikembangkan dan untuk mengetahui konsep yang sesuai dalam melakukan pengembangan dengan mempertimbangkan kondisi disekitar lahan.

Letak Objek Studi berada di Kota Administrasi Jakarta Utara, berada pada dua Kecamatan yaitu Kecamatan Penjaringan dan Kecamatan Pademangan dan berada pada Jl. Maritim Raya, RT.11/RW.08, Kota Tua, Jakarta Utara. Dengan total luas area pelabuhan sebesar 50,8 Ha dan luas fasilitas komersial yang akan dikembangkan berupa mall terbatas sebesar 1,2 $\mathrm{Ha}$. 


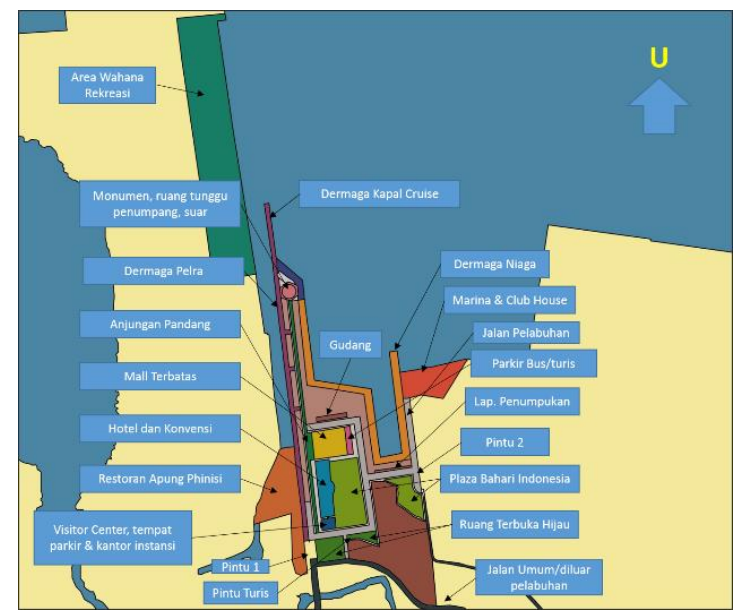

Gambar 2 Rencana Induk Kawasan Pelabuhan Sunda Kelapa

Sumber : KSOP Pelabuhan Sunda Kelapa

\section{KAJIAN LITERATUR}

Pada bagian ini akan dibahas mengenai kajian literatur yang akan digunakan sebagai landasan dalam melakukan pengembangan mall terbatas di Area Pelabuhan Sunda Kelapa.

\section{Pengertian Pengembangan}

Menurut Kamus Tata Ruang, pengembangan merupakan sebuah proses pemekaran (kuantitatif) dan perbaikan (kualitatif), bisa juga diartikan sebagai suatu proses perbaikan atas suatu lahan. Pengembangan dan pengelolahan kawasan merupakan suatu seni untuk merencanakan, mengorganisir, mengendalikan suatu kawasan dalam rangka mempertahankan nilai investasi beserta pengembanliannya yang bertujuan untuk mendapatkan profit bukan hanya finansial atau bisnis semata-mata tetapi juga nilai sosial.

Pengembangan wilayah merupakan strategi memanfaatkan dan mengkombinasikan faktor internal (kekuatan dan kelemahan) dan eksternal (peluang dan tantangan) yang ada sebagai potensi dan peluang yang dapat dimanfaatkan untuk meningkatkan produksi wilayah akan barang dan jasa yang merupakan fungsi dari kebutuhan baik secara internal maupun eksternal wilayah. Faktor internal ini berupa sumber daya alam, sumber daya manusia dan sumber daya teknologi, sedangkan faktor eksternal dapat berupa peluang dan ancaman yang muncul sering dengan interkasinya dengan wilayah lain. (Mike E. Miles, 2007)

Proses pengembangan real estate menurut Urban Land Institute terdiri dari : (Urban Land Institute, 1998)

1. Tahapan gagasan atau permulaan ide

a. Permulaan ide

b. Ide Khusus (misal proyek perkantoran atau gedung hotel)

c. Mempertimbangkan proyek yang sesuai dengan kawasan yang akan dikembangkan atau sebaliknya.

d. Target pasar dan kemungkinan sumber keuangannya.

e. Pada tahap ini dinekal istilah "Pro Forma" yaitu terdiri dari :

- Biaya dan pendapatan penentuan besarnya nilai proyek

- Persiapan biaya penentuan besarnya nilai proyek

- Kebutuhan penyewa

- Persyaratan kontruksi

- Nilai proyek ditentukan berdasarkan tingkat kapitalis yang berlaku saat proyek ditentukan.

- Ketentuan tersebut disusun dalam bentuk cash flow 
2. Studi Kelayakan

- Jika ide yang bersifat masih kasar/global terlihat menguntungkan, maka dilanjutkan ke langkah kedua

- Memperbaiki ide atau konsep pada langkah pertama yang bersifat masih kasar/global

- Menentukan lokasi dari alternatif-alternatif lokasi yang ada

- Tanah tersebut harus esuai dengan zoning Rencana Tata Ruang

- Harus ada pencapaian ke jalan arteri, jalur transportasi utama, dan jalur pelayanan kota

3. Tahap Perencanaan Umum

- Tahap pra perjanjian

- Studi kelayakan (melakukan berbagai riset pasar)

- Menggunakan data ekonomi regional dan perkotaan

- Persiapan gambar arsitektural

- Tender kontruksi

- Persetujuan atas ijin bangunan dan pemenuhan syarat atau peraturan pemda setempat

4. Tahap analisis pembiayaan dan kontrak

- Meliputi semua persetujuan dengan semua pihak yang terlibat dalam proyek

- Pemenuhan ikatan perjanjian terhadap pinjaman tetap

- Peminjaman tetap tergabung dalam studi kelayakan developer, demikian pula pada analisa dan penilaiannya sendiri terdapat area tanah dan proyek

- Developer memperoleh pinjaman kontruksi

5. Tahap kontruksi

- Ikatan perjanjian dilaksanakan

- Persetujuan kerja sama ditutup

- Setiap penjualan pada investor positif ditutup

- Pinjaman kontruksi ditutup dan semua ikatan pembayaran tetap yang mengikat pinjaman tetap

- Kontrak kontruksi ditandatangani kontraktor umum

- Setiap penyewa yang ditentukan membayar kontrak mereka

- Peralihan sistem akunting dari sistem informasi pada saat tahap pro form ke sistem akunting formal

6. Tahap Pemasaran

- Pokok-pokok perjanjian sudah berlaku pada saat ini, developer lebih berfungsi sebagai seorang promotor

- Struktur fisik bangunan di bangun

- Setiap periode, sub kontraktor menyerahkan kwintansi atau vouucher mereka kepada kontraktor umum

- Pada tahap ini kerjasama antara manager kontruksi, perwakilan pemasaran, petugas keuangan, dan semua anggota tim pelaksana sangat dibutuhkan

7. Tahap Pemeliharaan

- Merupakan tahap akhir pengembangan

- Tahap kontruksi selesai

- Persyaratan tata kota seperti pengawasan dan sertifikat pemakaian telah dipenuhi

- Penyewa mulai menempati bangunan

\section{Properti Komersial}

Properti komersial adalah properti yang diatasnya di jadikan sebagai tempat untuk membuat keuntungan bagi si pemiliknya seperti ruko (rumah toko) yang dijadikan sebagai sebagai tempat 
untuk membuka usaha, perhotelan yang di jadikan sebagai tempat penginapan, rumah koskosan atau apartment yang disewakan sehingga selalu memberikan penghasilan setiap hari ataupun setiap bulannya bagi pemilik peroperti tersebut. (Tambunan, 2014).

\section{Pusat Perbelanjaan}

Pusat perbelanjaan adalah sebuah kumpulan pertokoan yang terencana dan dikelolah oelh sebuah management yang menyewakan unit-unit kepda pedagang dan dalam hal-hal tertentu pengawasannya dilakukan oleh manager yang sepenuhnya bertanggung jawab kepda pusat perbelanjaan tersebut. (Beddington, 1991). Menururt International Council of Shopping Center (ICSC) di United States, mall terbagi menjadi 4 menurut kegunaannya yaitu General-Purpose Centers, Specialized-Purpose Center, Limited-Purpose Property dan Total Industry.

\section{Theme Center}

Theme Center merupakan salah satu klasifikasi dari pusat perbelanajaan yang dikeluarkan oleh International Council of Shopping Center di Amerika. Menurut ICSC, shopping center terbagi dari 4 menurut jenisnya yaitu :

a. General - Purpose Centers

b. Specialized-Purpose Centers

c. Limited-Purpose Centers

d. Total Indusrty

Lalu terdapat beberapa jenis pusat perbelanjaan yang termasuk dalam Specialized - Purpose Center. Beberapa ini merupakan jenis shopping mall yang termasuk ke dalam Specialized Purpose Center beserta dengan karakteristiknya :

a. Power Center

Konsep dari Power center yaitu shopping center dengan ancor yang dominan termasuk separtment store yang dapat memberikan discount, toko dengan harga yang rendah dan beberapa tenat kecil lainnya. Luas dari Power Center yaitu rata-rata sekitar $438.626 \mathrm{~m}^{2}$ atau sebesar 4, $4 \mathrm{Ha}$. Jenis ancor yang biasanya berada pada Power Center adalah toko perlengkapan rumah tangga, department store kecil, dan toko dengan harga yang murah.

b. Lifestyle Centers

Konsep dari Lifestyle Center yaitu shopping center yang diisi dengan toko brand mewah dalam negeri dengan tempat makan dan entertainment / hiburan yang berada pada daerah outdoor / terbuka. rata - rata luasa dari Lifestyle Center adalah sebesar 335.852 $\mathrm{m}^{2}$ atau sebesar $3,4 \mathrm{Ha}$. Jenis ancor yang biasanya berada pada lifestyle mall adalah toko besar dengan brand dalam negeri.

c. Factory Outlet

Konsep dari Factory Outlet yaitu shopping center yang bergerak pada toko yang menjual berbagai jenis brand terkenal dengan harga yang murah / telah di diskon. Luas rata rata dari factory Outlet adalah $238.060 \mathrm{~m}^{2}$ atau sebesar $2.4 \mathrm{Ha}$. Jenis ancor yang berada pada Factory Outlet adalah toko - toko pakaian.

d. Theme / Festival Centers

Konsep dari Theme / Fetival Center yaitu shopping mall yang berorientasi pada kenyamanan, touris, toko dan hiburan sebagai bagian dalam konsepnya. Berada di area perkotaan, daerah atau bangunan bersejarah dan merupakan bagian dari proyek Mixed - Use. Luas rata - rata dari Theme Center adalah $147.791 \mathrm{~m}^{2}$ atau sebesar 1,4 Ha. Biasanya ancor yang berada pada Theme Center adalah untuk tempat makan dan hiburan / entertainment. 


\section{Konsep Highest dan Best Use}

HBU didefinisikan sebagai penggunaan yang paling mungkin dan optimal dari suatu aset, yang secara fisik dimungkinkan, telah dipertimbangkan secara memadai, secara hukum diijinkan, secara financial layak, dan menghasilkan nilai tertinggi dari aset tersebut ((MAPPI), 2018). Dengan kata lain Highest amd Best Use dapat diartikan sebgai penggunaan lahan yang paling optimal yang diijinkan secara hukum dan layak dari segi keuangan yang akan menghasilkan nilai lahan tertinggi dari pengembangan lahan tersebut.

Highest and Best Use dari sebuah properti didefiniskan sebagai memiliki ijin secara hukum dan peraturan, memungkinkan secara fisik, memiliki kelayakan finansial, dan dapat berproduksi secara maksimal. Prinsip dari highest dan best use adalah nilai pasar dari sebuh properti adalah fungsi dari pengunaan yang paling produktif (David C. Ling, 2017). Analisis highest and best use menentukan pengunaan tertinggi dari lahan yang dinilai dan optimal dari segi ekonomi berdasarkan nilai tersebut. Tiga macam pendekatan dalam melakukan penilaian mengukur nilai highest and best use dari properti yang dinilai.

Menurut David C. Ling, kriteria konsep highest and best use dari sebuah properti mencakup (David C. Ling, 2017) :

a. Diijinkan secara hukum (legal permissible)

Pengembangan suatu bangunan yang tidak melanggar peraturan yang ditetapkan pemerintah, seperti peraturan peruntukan lahan, KDB, KLB, batas ketinggian maksimal, GSB, dan lain-lain.

b. Memungkinkan pelaksanaannya secara fisik (physically permissible)

Perencanaan fisik bangunan layak dilaksanakan dan sudah memenuhi seluruh persyaratan teknis pembangunan sesuai peruntukannya.

c. Layak dari segi financial (financial permissible)

Secara keuangan dapat memberikan keuntungan yang optimal dengan waktu pengembalian modal yang relatif lebih cepat, sehingga dapat menjadikan investasi lebih menarik.

d. Menghasilkan pendapatan tertinggi (maximally productive)

Pengembangan properti tersebut dapat menghasilkan pendapatan yang meksimal karena terdapat pasar yang potensial saat ini maupun di masa yang akan datang.

Berdasarkan kriteria diatas, faktor utama yang menjadi acuan investor adalah kriteria ketiga dan keempat. Oleh karena itu faktor supply dan demand properti yang sudah berjalan maupun yang sedang dalam tahap perencanaa, perilaku konsumen, serta karakteristik lahan yang akan dikembangkan sangat terpengaruh dalam melakukan analisa kedua kriteria tersebut.

a. Lahan / tanah kosong

Bertujuan untuk mengidentifikasikan penggunaan lahan yang nantinya akan menentukan nilai tanah. Hal ini diperlukan pada suatu penentuan nilai tanah secara terpisah dan pada saat penentuan nilai tanah secara terpisah dan pada saat sejumlah tanah kosong pembanding baru saja terjual dan diperlukan identifikasi.

b. Properti yang sudah beridiri

Bertujuan untuk mengetahui pengunaan yang diharapkan untuk menghasilkan pengembalian terbesar dari sejumlah modal yang diinvestasikan, serta membantu penilai dalam memilih properti pembanding.

\section{METODE}

Pada bagian ini akan membahas mengenai teknik pengumpulan data selama proses penelitian / desain dan menjelaskan mengenai metode pengumpulan data. 


\section{Jenis dan Teknik Pengumpulan Data}

Dalam melakukan studi ini, diperlukan teknik pengumpulan data agar data yang dikumpulkan dapat secara tepat dan lengkap sesuai dengan kebutuhan studi. Metode pengumpulan data yang digunakan dalam penelitian ini terbagi menjadi dua, yakni data premier dan data sekunder.

\section{Data Primer}

Data primer merupakan data yang diperoleh dengan melakukan pengamatan secara langsung terhadap objek studi. Data yang diperoleh dapat berupa data kuantitatif dan kualitatif. Pegumpulan data premier dapat dilakukan dengan beberapa metode, yaitu

\section{a. Survey Lapangan}

Survey lapangan dilakukan dengan mengamati secara langsung objek studi. Melalui metode ini, peneliti dapat dengan mudah memahami kondisi eksisting objek studi. Dalam studi ini, survey lapangan dilakukan pada objek studi yang telah dipilih, yaitu Pelabuhan Sunda Kelapa. Melalui survey lapangan, data primer berupa data kondisi lingkungan sekitar tapak dapat dikumpulkan.

\section{b. Wawancara}

Wawancara dilakukan untuk memperdalam data primer yang sudah didapatkan melalui survey lapangan terlebih dahulu. Dalam metode ini, peneliti harus menyiapkan daftar pertanyaan untuk memperoleh data data yang tidak dapat diberikan tanpa ijin dari narasumber yang bersangkutan. Dalam studi ini, wawancara dilakukan salah satunya oleh KSOP Pelabuhan Sunda Kelapa sebagai penanggung jawab. Data yang diharapkan untuk diperoleh melalui wawancara yaitu data yang berkaitan dengan legalitas lahan dan rencana pengembangannya.

\section{c. Dokumentasi}

Dokumentasi dilakukan untuk menunjang dari metode survey lapangan dan wawancara. Data-data yang dikumpulkan dengan menggunakan metode tersebut dapat didokumentasikan dalam bentuk data visual seperti foto. Hasil Dokumentasi tersebut dapat digunakan untuk menggambarkan kondisi eksisting dari objek studi secara visual.

\section{Data Sekunder}

Data sekunder merupakan data yang dapat diperoleh secara tidak langsung melalui media. Media yang digunakan dapat berupa media cetak dan elektronik (internet), serta data dari institusi yang terkait dengan objek studi.

Dalam studi ini membutuhkan data yang sesuai dengan kebutuhan analisis yang akan dilakukan sehingga perlu diketahui ketersediaan data dan disesuaikan dengan kemampuan pengumpulan data baik data primer maupun data sekunder.

\section{Teknik Pengelolahan Data}

Teknik pengelolahan yang dipakai dalam membuat artikel ini terdiri dari beberapa tahap, yaitu

a. Analisis Lokasi dan Tapak

Pada analisis ini bertujuan untuk membahas lokasi dan tapak dari Pelabuhan Sunda Kelapa dari segi lokasi dan tapak, sehingga dapat mengetahui potensi dan permasalahan utama dari luar (eksternal) dan dalam (internal) kawasan. Pada pembahasan luar kawasan (eksternal) membahasa mengenai karakteristik lokasi, pencapaian, proximity, rencana kota dan arah pengembangan kota. Sedangkan pada pembahasan dalam kawasan (internal) membahas mengenai karakteristik tapak, pencapaian dan sirkulasi, visual tapak, aktifitas lingkungan, kapastitas ruang dan nilai lahan. Setelah dilakukan analisis ini maka dirumuskan dalam potensi dan permasalahan utama dengan menggunakan metode analisis deskriptif dan SWOT. 
b. Analisis Legalitas

Analisis legalitas yang dilakukan adalah untuk membahas mengenai pengembangan sesuai dengan peraturan kota yang telah ada sepert RDTR 2030 dan RTRW 2030. Tujuan analisis ini adalah untuk mengetahui kelayakan dari aspek segi legalitas mengenai pengembangan yang akan dilakukan. Analisis ini menggunakan metode deskriptif.

c. Analisis Pasar

Analisis pasar yang dilakukan adalah analisis pasar mikro, yang akan membahas lebih fokus langsung pada objek studi. Di dalam analisis pasar terdapat analisis kondisi demografi, makro ekonomi, market positioning, competitive Level dan market share, profil Pelabuhan Sunda Kelapa. Analisis pasar akan menggunakan metode STP.

\section{DISKUSI DAN HASIL}

Pada bagian ini akan membahas mengenai temuan penelitian dari studi kelayakan dari proyek yang akan dikembangkan dari aspek legalitas, lokasi dan pasar agar pengembangan yang dilakukan sesuai dan layak untuk dikembangkan.

\section{Analisis Legalitas}

Berdasarkan RDTR 2030 Kecamatan Pademangan, peruntukan lahan diarahkan sebagai kawasan perkantoran, perdagangan, dan jasa dan kawasan industri dan pergudangan. Sedangkan pada RTRW 2030, lahan diarahkan menjadi kawasan perkantoran, perdagangan, dan jasa. Berikut ini merupakan gambar lahan menurut RDTR 2030 dan RTRW 2030.

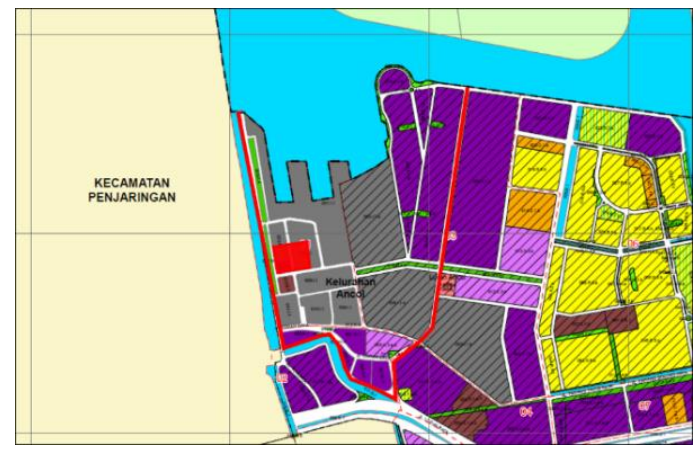

Gambar 3. Rencana Penggunaan Lahan Menurut RDTR 2030

Sumber : RDTR Kecamatan Pademangan 2030

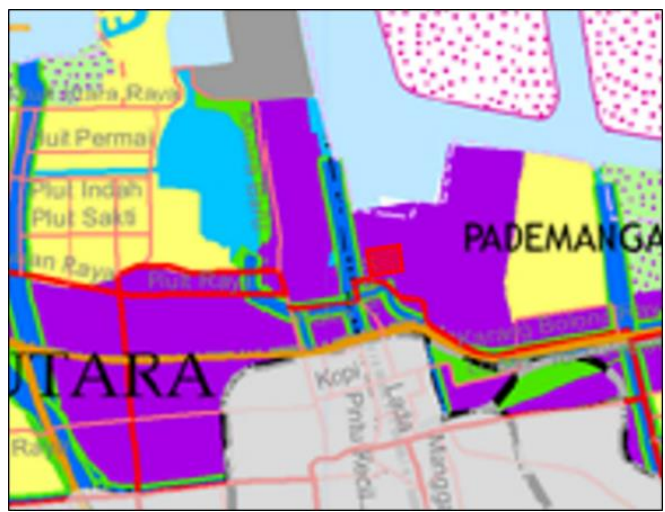

Gambar 4. Rencana Penggunaan Lahan Menurut RTRW 2030

Sumber : RTRW Kota Jakarta Utara 2030

Sedangkan menurut dari Rencana Induk Kawsan Pelabuhan Sunda Kelapa, objek studi diarahkan untuk menjadi mall terbatas. Berikut ini merupakan Rencana Induk Kawasan Pelabuhan Sunda Kelapa : 


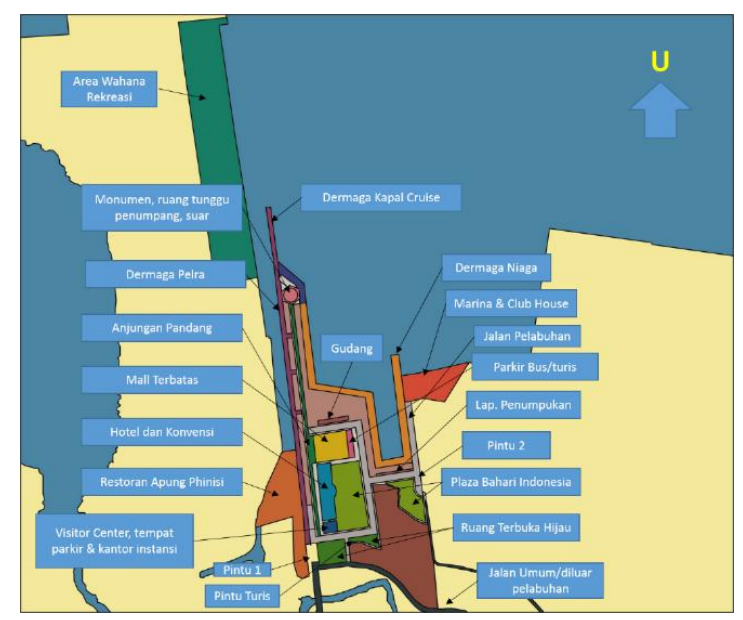

Gambar 5. Gambar Rencana Induk Kawasan Pelabuhan Sunda Kelapa

Sumber : Rencana Induk Kawasan Pelabuhan Sunda Kelapa

Jika pada lokasi objek studi dibandingkan antara Rencana Induk Kawasan dan RDTR 2030 yang memiliki zonasi K.1 yang merupakan kawasan komersial dan I.1 yang merupakan kawasan industri maka pengembangan tidak sesuai dengan zonasinya, namun jika dilihat dari RTRW 2030 yang seluruh Pelabuhan Sunda Kelapa merupakan komersial maka dapat disimpulkan bahwa pengembangan memungkin untuk dilakukan dikarena terdapat acuan yang sesuai antara rencana induk kawasan dan RTRW 2030 sehingga memungkinkan untuk diberikan rekomendasi untuk perubahan zonasi.

Tabel 1. Intensitas Lokasi Tapak Menurut RDTR 2030

\begin{tabular}{cccccc}
\hline Zona & ID Subblock & KDB & KLB & KB & KDH \\
\hline $\begin{array}{c}\text { Zona Industri dan } \\
\text { Pergudangan }\end{array}$ & 01.001. I.1 & 50 & 2,00 & 4 & 30 \\
\hline $\begin{array}{c}\text { Zona Industri dan } \\
\text { Pergudangan }\end{array}$ & 01.002 .1 .1 & 50 & 2,00 & 4 & 30 \\
\hline $\begin{array}{c}\text { Zona Perkantoran, } \\
\text { Perdagangan, dan Jasa }\end{array}$ & $01.004 . K .1$ & 50 & 2,00 & 4 & 30 \\
\hline
\end{tabular}

Sumber : RDTR 2030 Kecamatan Pademangan

\section{Analisis Pasar}

Berikut akan dijelaskan mengenai analisis pasar yang akan dilakukan dalam rangka untuk menentukan target pasar dan konsep pengembangan yang sesuai dengan kondisi di sekeliling Area Pelabuhan Sunda Kelapa.

\section{Analisis Demografi}

Pelabuhan Sunda Kelapa berada pada dua kecamatan yang berbeda yaitu Kecamatan Penjaringan dan Kecamatan Pademangan. Berikut merupakan tabel jumlah kependudukan menurut kecamatan dan jenis kelamin.

Tabel 2. Mengenai Kependudukan di Kecamatan Penjaringan

\begin{tabular}{ccccccc}
\hline No. & Kelurahan & $\begin{array}{c}\text { Luas Area } \\
(\mathbf{K m 2})\end{array}$ & Laki-laki & $\begin{array}{c}\text { Penduduk } \\
\text { Perempuan }\end{array}$ & Jumlah Total & $\begin{array}{c}\text { Rasio Jenis } \\
\text { Kelamin }\end{array}$ \\
\hline $\mathbf{1}$ & Kamal Muara & 10,594 & 6.961 & 6.728 & 13.689 & 103,46 \\
\hline $\mathbf{2}$ & Kapuk Muara & 10,055 & 19.630 & 18.979 & 38.609 & 103,43 \\
\hline $\mathbf{3}$ & Pejagalan & 3,2318 & 44.709 & 43.752 & 88.461 & 102,19 \\
\hline
\end{tabular}




\begin{tabular}{ccccccc}
\hline No. & Kelurahan & $\begin{array}{c}\text { Luas Area } \\
\mathbf{( K m 2 )}\end{array}$ & Laki-laki & $\begin{array}{c}\text { Penduduk } \\
\text { Perempuan }\end{array}$ & Jumlah Total & $\begin{array}{c}\text { Rasio Jenis } \\
\text { Kelamin }\end{array}$ \\
\hline $\mathbf{4}$ & Penjaringan & 3,9543 & 55.111 & 50.666 & 105.777 & 108,77 \\
\hline $\mathbf{5}$ & Pluit & 7,7119 & 25.610 & 26.343 & 51.953 & 97,22 \\
\hline & Total & 35,547 & 152.021 & 146.468 & 298.489 & 515,07 \\
\hline
\end{tabular}

Sumber : Kecamatan Penjaringan dalam angka 2018

Tabel 3. Mengenai Kependudukan di Kecamatan Penjaringan

\begin{tabular}{|c|c|c|c|c|c|c|}
\hline \multirow[t]{2}{*}{ No. } & \multirow[t]{2}{*}{ Kelurahan } & \multirow{2}{*}{$\begin{array}{c}\text { Luas Area } \\
\text { (Km2) }\end{array}$} & \multicolumn{3}{|c|}{ Penduduk } & \multirow{2}{*}{$\begin{array}{l}\text { Rasio Jenis } \\
\text { Kelamin }\end{array}$} \\
\hline & & & Laki-laki & Perempuan & $\begin{array}{c}\text { Jumlah } \\
\text { Total }\end{array}$ & \\
\hline 1 & Pademangan Barat & 3,5335 & 46.190 & 43.315 & 89.505 & 106,63 \\
\hline 2 & Pademangan Timur & 2,6124 & 21.232 & 21.232 & 42.464 & 100,27 \\
\hline 3 & Ancol & 3,7728 & 14.840 & 14.840 & 29.680 & 109,17 \\
\hline & Total & 9,9187 & 82.262 & 79.387 & 161.649 & 316,07 \\
\hline
\end{tabular}

Sumber : Kecamatan Penjaringan dalam angka 2018

\section{Analisis Demand}

Potensi demand yang berada di Pelabuhan Sunda Kelapa terdiri dari beberapa sumber deman yaitu dari Rencana Induk Kawasan Kotatua dan wisatawan yang menggunakan kapal cruise.

\section{Rencana Induk Kawasan Kotatua}

Berikut ini merupakan Rencana Induk Kawasan Kotatua yang telah ditetapkan pada Pergub 36 Tahun 2014 mengenai Rencana Induk Kawasan Kotatua. Berikut ini merupakan RIK Kotatua yang berkaitan dengan pengembangan yang akan dilakukan pada Pelabuhan Sunda Kelapa :

a. Mengembangkan fungsi komersial yang menunjang wisata kesejarahan bahari pada sisi utara salah satunya Sunda Kelapa.

b. Kegiatan komersial yang tidak bersifat mengancam kelestarian lingkungan dan kawasan, khususnya terkait kemampuan daya dukung lahan dan kehadiran kendaraan - kendaraan berat atau besar.

c. Memperkuat peran Ruang Terbuka Hijau (RTH) salah satunya pada kawasan Sunda Kelapa.

d. Manata RTH di Kawasan Sunda Kelapa sebagai kawasan wisata pelabuhan.

e. Memperkuat gerbang utara dari arah laut yang dibentuk kawasan oleh Sunda Kelapa

f. Menghidupkan kembali pusat aktivitas di Pasar Ikan, Menara Syahbandar, dan Pelabuhan Sunda Kelapa sebagai pusat aktifitas di utara kawasan sebagai fungsi wisata bahari.

g. Membuat jalan ringroad tahap dua meliputi jalan tembus melalui Pelindo dan recana jalan tembus di sisi timur kali Ciliwung menuju jalan Muka Timur.

h. Badan air berupa asaluran, kali, sungai, banjir kanal, situ, dan waduk tidak dapat diubah peruntukannya.

Selain itu pada pasal 11 mengenai konsep pengembangan zona, area di dalam tembok (kawasan taman fatahillah dan sekitarnya, kawasan stasiun Beos dan sekitarnya, Koridor Kali Besar dan sekitarnya, Kawasan Sunda Kelapa dan sekitarnya) terdiri dari zona penunjang yang pengembangannya diarahkan sebagai kawasan bersejarah dengan fungsi utama sebagai fungsi edukasi, kegiatan budaya dan sosial, ikon wisata Internasional, replikasi Kota Lama Batavia, pusat bisnis dan perdagangan terbatas.

Lalu pada pasar 17 mengenai Rencana Pengembangan Kawasan Komersial menjelaskan mengenai :

a) Fungsi komersial terdiri atas kawasan dengan pemanfaatan sebagai perkantoran, perdagangan dan jasa serta campuran. 
b) Rencana Pengembangan kawasan komersial sebagaimana dimaksud pada ayat (1) bertujuan untuk :

a. Menciptakan iklim yang kondusif bagi para penanam modal lokal dan asing didukung oleh sarana dan prasarana yang memadai; dan

b. Mengalokasikan kebutuhan ruang bagi sektor informal dan golongan usaha kecil terpadu dengan pengembangan sekor formal yang lebih besar.

c) Pengembangan kawasan komersial sebagaimana dimaskud pada ayat (2) dilakukan melalui

a. Memberikan fungsi baru tanpa megubah karakter morfologi penting pada kawasan atau bangunan;

b. Fungsi komersial diarahkan berupa fungsi - fungsi yang dapat menonjolkan karakter kawasan sebagai kawasan pariwisata dan sejarah seperti Tourist Center, Visitor Center, Hotel, Museum, Restaurant, Boutique;

c. Fungsi Komersial dianjurkan berupa fungsi yang mampu menghidupkan kawasan selama 24 (dua puluh empat) jam, misalkan : Hotel, Apartment, Hiburan, Pertokoan, Perbelanjaan; dan

d. Mengarahkan jenis usaha komersial mendukung sesuai dengan arahan pengembangan area.

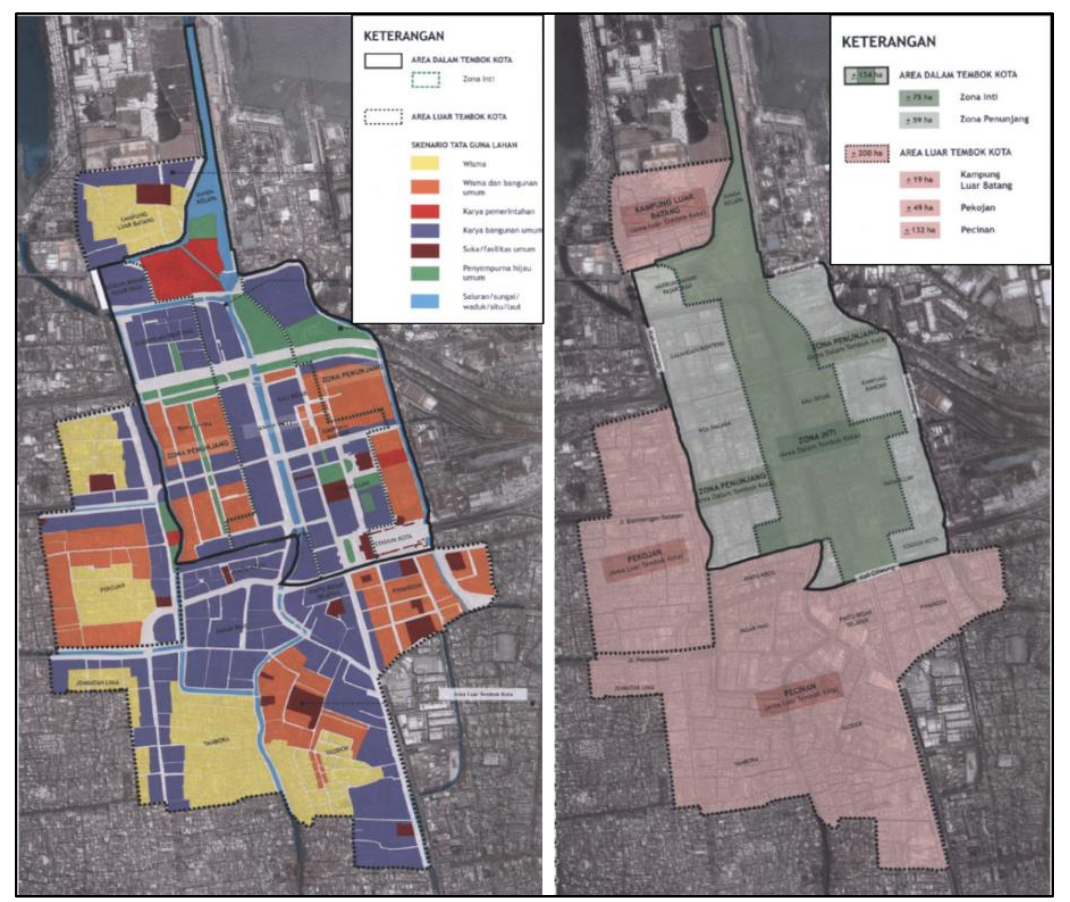

Gambar 6. Rencana Induk Kawasan Kotatua

Sumber : Pergub 36 Tahun 2014 Mengenai Rencana Induk Kawasan Kotatua

\section{Wisatawan Kapal Cruise}

Berdasarkan jadwal kedatangan kapal cruise / kapal pesiar yang akan mengunjungi Indonesia pada tahun 2019 - 2020, Pelabuhan Tanjung Benoa merupakan pelabuhan dengan jumlah kedatangan dan jumlah pengunjung terbanyak diantara 40 pelabuhan lainnya yang mengunjungi Indonesia.

Untuk kedatangan kapa cruise yang mengunjungi pelabuhan di pulau jawa pada tahun 2019 - 2020, Pelabuhan Tanjung Emas yang berada di Semarang merupakan pelabuhan dengan tingkat kedatangan dan jumah penumpang paling banyak dibandingkan dengan dengan pelabuhan lainnya. Berikut merupakan jumlah kedatangan dan jumlah wisatawan yang mengunjungi pelabuhan yang berada di Pulau Jawa. 
Tabel 4. Tabel Kedatangan dan Keberangkatan Kapal Cruise Menuju Pulau Jawa Pada Tahun

\begin{tabular}{|c|c|c|c|c|c|c|c|c|}
\hline \multicolumn{9}{|c|}{$2019-2020$} \\
\hline \multirow[t]{2}{*}{ Lokasi } & & 2019 & & Persentase & & 2020 & & Persentase \\
\hline & $\begin{array}{c}\text { Jumlah } \\
\text { Kedatang } \\
\text { an }\end{array}$ & $\begin{array}{c}\text { Persentase } \\
\text { Jumlah } \\
\text { Kedatangan } \\
\text { (\%) }\end{array}$ & $\begin{array}{l}\text { Jumlah } \\
\text { Penump } \\
\text { ang }\end{array}$ & & $\begin{array}{c}\text { Jumlah } \\
\text { Kedatang } \\
\text { an }\end{array}$ & $\begin{array}{c}\text { Persentase } \\
\text { Jumlah } \\
\text { Kedatangan } \\
\text { (\%) }\end{array}$ & $\begin{array}{c}\text { Jumlah } \\
\text { Penump } \\
\text { ang }\end{array}$ & \\
\hline Surabaya & 6 & 17,14 & 6300 & 26,21 & 11 & 21,15 & 13783 & 26,96 \\
\hline Semarang & 12 & 34,29 & 10240 & 42,59 & 24 & 46,15 & 24261 & 47,46 \\
\hline Probolinggo & 12 & 34,29 & 4472 & 18,60 & 10 & 19,23 & 6183 & 12,10 \\
\hline Jakarta & 5 & 14,29 & 3029 & 12,60 & 7 & 13,46 & 6893 & 13,48 \\
\hline TOTAL & 35 & 100 & 24041 & 100 & 52 & 100 & 51120 & 100 \\
\hline
\end{tabular}

Sumber : www.cruisemapper.com

Dari tabel diatas menunjukkan bahwa pada tahun 2019, kedatangan kapal cruise paling banyak di Pulau Jawa yaitu untuk menuju Semarang dan Probolinggo sebesar 34,29\% dan untuk jumlah wisatawan yang datang menggunakan kapal cruise paling banyak yaitu untuk menuju Kota Semarang sebesar 42,59 \% dari total keseluruhan wisatawan yang datang ke Pulau Jawa. Lalu untuk tahun 2020 menunjukkan bahwa bahwa kedatangan kapal cruise paling banyak yaitu menuju Kota Semarang sebesar 46,15 dari total kedatangan ke Pulau Jawa dan untuk jumlah wisatawan yang datang menggunakan kapal cruise paling banyak menuju Kota Semarang sebesar 47,46 \% dibandingkan dsetinasi lainnya di Pulau Jawa yang menjadi destinasi kapal cruise.

\section{Analisis Konsep Pengembangan}

Analisis Konsep Pengembangan terhadap Rencana Induk Kawasan akan membahas mengenai hasil dari analisis konsep pengembangan berdasarkan obej studi pembanding/Benchmark lalu akan dibandingkan dengn Rencana Induk Kawasan Pelabuhan Sunda Kelapa yang telah direncanakan.

Jika dilihat dari analisis yang sebelumnya sudah dilakukan maka didapatkan hasil bahwa mall yang menjadi objek studi pembanding sebagian besar tenatnya didominasi oleh food and drink, fashion dll. Selain itu demand yang ditaergetkan yaitu untuk para turis dari dalam negri atau dari luar negri yang berlabuh dari dermaga cruise sehingga kelas Theme Center yang akan ditawarkan yaitu mall dengan kelas premium. Dibawah ini merupakan rencana yang telah ditentukan diambil dari Rencana Induk Kawasan Pelabuhan Sunda Kelapa :
a. Lantai 1 : Pasar Ikan
b. Lantai 2 : Toko / Supermarket terbatas
c. Lantai 3 : Restaurant / Foodcourt Seafood
d. Lantai 4 : Museum
e. Lantai 5 : Ruang tungu penumpang

Jika dilihat dari demand yang ditargetkan untuk objek studi yang diteliti yaitu mall terbatas dengan konsep Theme Center yang berada di Area Pelabuhan Sunda Kelapa maka didapatkan hasil bahwa kelas mall yang akan dikembangkan adalah kelas menengah dalam rangka menciptakan pusat kegiatan baru pada daerah utara Jakarta dan karena Pelabuhan Sunda Kelapa masuk ke dalam Pergub 36 Tahun 2014 yang merencanakan kawasan Pelabuhan Sunda Kelapa akan dikembangkan menjadi kawasan pariwisata sejarah. Oleh karena dua faktor diatas maka didapatkan hasil bahwa rencana yang telah disusun oleh Rencana Induk Kawasan Pelabuhan Sunda Kelapa sudah tepat dalam memaksimalkan potensi dari Theme Center yang 
akan dikembangkan. Dalam aspek legalitas, area Theme Center mengacu pada RDTR 2030 yaitu hanya diperbolehkan 4 lantai dengan KDB sebesar 50\% dan KLB 2 sehingga rencana ruang yang di rencanakan oleh RIK Pelabuhan Sunda Kelapa melangar peraturan jika dibangun setinggi 5 lantai.

\section{KESIMPULAN DAN SARAN}

\section{Layak Secara Teknis}

Kesimpulan yang dapat diambil dari analisis lokasi dan tapak, dan analisis legalitas yaitu :

- Lokasi yang berada di Pelabuhan Sunda Kelapa dinilai layak dalam dikembangkan Theme Center karena letaknya yang berada di area sejarah dan masuk kedalam salah satu dari beberapa tempat wisata unggulan menurut provinsi DKI Jakarta dan juga direncakan sebagai tempat wisata seperti yang tertera pada Pergub 36 Tahun 2014 mengenai Rencana Induk Kawasan Pelabuhan Sunda Kelapa.

- Aksesbilitas yang di sekitar Pelabuhan Sunda Kelapa juga mendukung karena pada rencana yang tertera pada RDTR 2030 tertera rencana mengenai rencana jalur Transjakarta yang nantinya akan terintegrasi dengan jaringan MRT fase II dan Fase I.

- Untuk proximity, letak Pelabuhan Sunda Kelapa dinilai cukup strategis karena dekat dengan exit tol dan beberapa jenis fasilitas pendukung lainnya pusat - pusat rekreasi dan perbelanjaan.

- Untuk analisis tapak dapat disimpulkan bahwa lahan memiliki posisi yang strategis karena memiliki salah satu aset peninggala sejarah pada bagian baratnya yaitu pelabuhan kapal phinisi yang sampai sekarang masi menjadi tujuan wisatawan dalam mengunjungi Pelabuhan Sunda Kelapa.

- Untuk analisis Igelitas dapat disimpulkan bahwa rencana induk yang dikembangkan oleh Pelabuhan Sunda Kelapa khususnya dalam pengembangan mall terbatas sudah sesuai dengan peraturan dan ketentuan yang ada.

Dari kesimpulan diatas dapat dikatakan bahwa pengembangan yang di lakukan pada area Pelabuhan Sunda Kelapa sudah sesuai dan layak secara teknis.

\section{Layak Secara Lingkungan / Pasar}

Kesimpulan yang dapat diambil dari analisis pasar, analisis konsep pengembangan dan analisis konsep pengembangan terhadap rencana induk yaitu:

- Jika dilihat dari analisis kondisi demografi, Pelabuhan Sunda Kelapa berada di Kota Jakarta Utara dan berada di antara Kecamatan Pademangan dan Kecamatan Penjaringa. Untuk jenis pekerjaan di wilayah Jakarta Utara paling tinggi yaitu dalam bidang perdagangan, rumah makan dan jasa akomodasi dikarenakan letaknya yang berbatas langung dengan laut Jawa pada bagian Utaranya.

- Jika dilihat dari analisis deman menurut Rencana Induk Kawasan Kotatua, Pelabuhan Sunda Kelapa difoukuskan sebagai tempat wisata bahari yang menjadi gerbang dalam pengembangan pusat kegiatan baru di wilayah utara. Dengan adanya potensi dari pengembangan kapal cruise dan Pelabuhan Sunda Kelapa yang telah masuk ke dalam pusat wisata unggulan menurut provinsi membuat pengembangan yang dilakukan di Pelabuhan Sunda Kelapa layak untuk dikembangkan sebagai tempat wisata.

- Jika dilihat dari analisis konsep pengembangan maka dapat dikatakan bahwa Pelabuhan Sunda Kelapa memiliki aspek yang sama dengan benchmark / properti sejenis yang telah dikembangkan, jadi pengembangan Pelabuhan Sunda Kelapa memiliki persamaan dalam mengait wisatawan untuk berkunjung kesana.

Dari kesimpulan diatas didapatkan bahwa pengembangan yang dilakukan di Pelabuhan Sunda Kelapa layak secara lingkungan / pasar, karena telah memiliki potensi dari lokasi dan sesuai dengan karakteristik lingkungannya. 


\section{REFERENSI}

Appraisal Institute. (2013). The Appraisal of Real Estate, 14th Edition. Appraisal Institute. Chicago: Appraisal Institute.

Architectural Press. David C. Ling, W. A. (2017). Real Estate Principle: A Value Approach. New York: McGraw-Hill Education.

Beddington, N. (1991). Shopping Center, Retail Development design and management. London: Butterworth Architecture

David C. Ling, W. A. (2017). Real Estate Principle: A Value Approach. New York: McGraw-Hill Education.

Eliya, G. (1995). Kamus Pariwisata. Jakarta: Citra Harta Prima.

Indonesia, N. G. (2018, Juni 22). National Geographic Indonesia. Diambil kembali dari National Geographic Indonesia: https://nationalgeographic.grid.id/read/13886122/sejarahpelabuhan-sunda-kelapa-dan-cikal-bakal-kota-jakarta?page=all

Indonesia, N. G. (2018, Juni 22). Sejarah Pelabuhan Sunda Kelapa dan Cikal Bakal Kota Jakarta. Diambil kembali dari National Geographic Indonesia: https://nationalgeographic.grid.id/read/13886122/sejarah-pelabuhan-sunda-kelapadan-cikal-bakal-kota-jakarta?page=all

Institute Of Real Estate Management. (2013). Principles Of Real Estate Management, Sixteenth Edition. Institute Of Real Estate Management.

Kasmir, J. (2003). Studi Kelayakan Bisnis. Jakarta: Prenada Media Group.

Lawson, F. R. (1976). Hotel, Motels and Condominiums : Design, Planning and Maintenance. New York: Architectural Press.

MAPPI. (2013). Kode Etik Penilaian Indonesia dan Standar Penilaian Indonesia Edisi VI. Jakarta: Kode Etik Penilaian Indonesia dan Standar Penilaian Indonesia Edisi VI.

Mike E. Miles, G. L. (2007). Real Estate Development: Principles and Process. Washington: Urban Land Institute.

Robert C. K. (2004). Property Management. Michigan: Dearborn Real Estate Education.

Setyo, R. (2015, May 15). Mengenal Berbagai Macam Produk Bisnis Property. Diambil kembali dari asriman.com: http://asriman.com/mengenal-berbagai-macam-produk-bisnisproperty/

Tambunan, P. (2014, Desember). Pengertian Properti Komersial. Diambil kembali dari Usahaproperti.com: http://www.usahaproperti.com/archives/ 